\title{
Isaac Bábel em três textos
}

Àpresentação de BORIS SCHNAIDERMAN

Isaac Bábel (1894-1940) é certamente um dos grandes nomes da literatura de nosso século, mestre sobretudo do relato curto, de cuja concisão o proprio Hemingway declarava ter inveja. No entanto, fuzilado como inimigo do povo, só voltou a ser publicado na União Soviética, de modo muito incompleto, a partir de 1957. Muitos dos seus escritos só apareceram na Rússia depois do intcio da glasnost, embora já existissem em publicaçōes ocidentais. Há nottcia de que está sendo preparada uma edição de sua obra completa, que é, aliás, pouco numerosa.

Ainda recentemente, havia um misterio muito grande em torno de sua biografia. A propria data de sua morte aparece errada em dicionários literários e enciclopédias publicados a partir dos fins da década de 1950, na base de informações dadas pelos órgãos oficiais (antes, até o seu nome era proibido).

Atualmente, já estão divulgados os materiais referentes a seu julgamento $e$ ao processo, com as atas dos interrogatorios (Ogoniók, No 39, 23 a 30/9/1989). Ao que tudo indica, foram destrutdos os textos em que estava trabalhando nos últimos anos, seqüestrados pela poltcia polttica, quando ele foi preso.

A autobiografia de Bábel apareceu em diversas edições soviéticas de seus escritos. Sua filha, Nathalie Bábel, que publicou uma coletânea dos escritos do pai, traduzidos para o inglês, em Isaac Babel, The Lonely Years (Farrar Straus \& Company, Nova York, 1964), afirma, numa introdução ao livro, que os fatos apresentados por ele nâo devem ser totalmente vertdicos, pois teria havido a intenção de apresentar um perfil adequado a um jovem escritor soviético, que não era membro do Partido Comunista. Ademais, diz ela, "he loved to confuse and mystify people". Assim, segundo lhe contara a mãe, o trabalho de Bábel na Tcheka seria "pure fabrication", e outras passagens também proviriam mais da imaginação que da vida real.

"Guedali" (de 1924) é um dos seus contos mais conhecidos e figura no livro que se tornou famoso no Ocidente como Cavalaria vermelha. A versão em português que transcrevemos apareceu primeiramente na Folha de S.Paulo em 18/1/1986, em $m$ nha tradução. Utilizamos o texto de Ízbranoie (Obras escolhidas), publicado pela Goslitidát (Editora Estatal de Obras Literárias), Moscou, 1957.

Os outros dois textos figuram na dissertação de mestrado de Paulo DalRi Peres, Isaac Bábel - Inéditos, defendida em 1976 (foi nela que encontrei também a informação sobre Hemingway), tendo sido "Froim Gratch" divulgado no Ocidente e só depois na União Soviética (v. nota do tradutor).

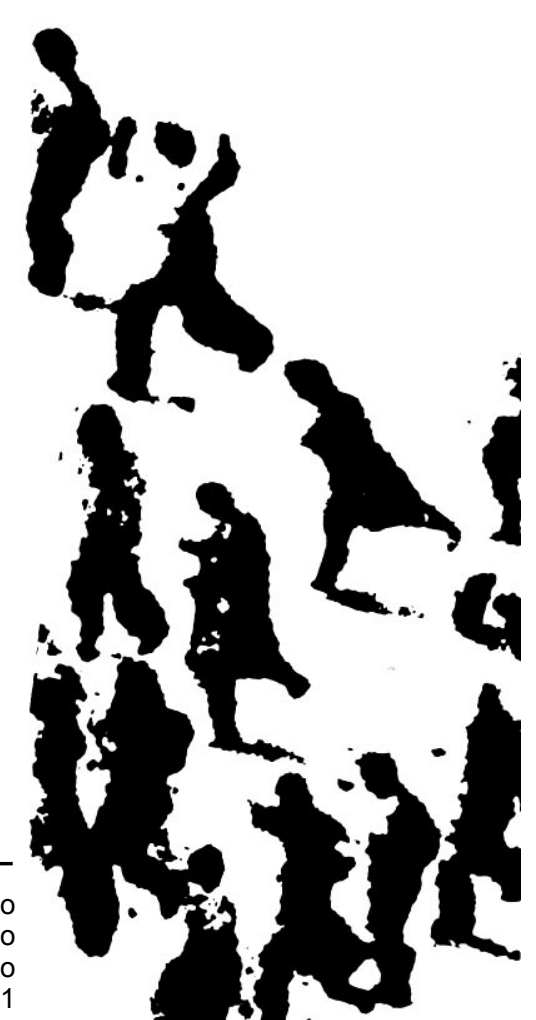




\section{Guedáli}

\section{Tradução e notas de BORIS SCHNAIDERMAN}

1 O fllosofo e poeta judeu espanhol Ibn-Ezra (1070-1130).

2 Rachi e o nome de um famoso comentarista da Bßblia e do Talmud, que viveu na França no séc. XI. Marmonides fol grande filosofo e teólogo judeu espanhol do séc. XII.

3 A primelra versăo desta autobiografia, escrita pelo autor em novembro de 1924, fol publicada no volume Pissâtoli: avtobiografli I portréti so vromitinh roskikh prozAlkov (Escritores: autoblografias $\theta$ retratos de prosadores russos contemporaneos) Sovremiennie problemi (Problemas atuals), Moscou, Ed. Vladimir Ldin, 1926. Fol republicada sem alteraçסes em I. E. Bábel - Státíi i Materiáli (I. E. Bábol - Artigos o materiais) . Babol - Artigos o materiais), Le ningrado, Academla, 1928. Na edlçăo das Obras escolhidas do escritor. da Editora Estatal de Obras Literárias, Moscou, 1957, omitiu-se todo um perfodo dela que, entretanto, reaparece em Escritores soviéticos, de 1959, da mesma editora. A se gunda versâ, datada de 1932 , fol encontrada no Arquivo Centri Oncontrada no Estado da Literatura e Arte da URSS. Trata-se de uma cópla datilografada da primelra versăo, com correçð̄es manuscritas do autor. $O$ confronto das duas versరoes permite observar que o método de reelaboraçăo de Bábel consistia mais em cortar do que em ecrescentar (delxamos entre barras as partes suprimidas). Em 1932. ras as partes suprimldas). Em 1932 . foram acrescentados apenas o áltimo parágrafo e a bibliografia, que atuaIlzam o texto.

40 perfodo omitido na ediçăo soviética de 1957.

5 Adeptos da corrente que se opós às inovaçరes introduzidas pelo patriarca Nicon na liturgia da Igreja Russa, no século XVII (1654).

6 Em francess no original.

7 Liêtopis (Anais, Crônica), revista de ciencias, literatura e polftica, dirigida e editada por Máximo Górkl, de janeiro de 1916 a dezembro de 1917.

8 Este artigo tratava da "pornografia". Bábel foi tambêm acusado segundo dois outros artigos referentes à "subversăo". Os contos sâo "llis lssáako vitch" i "Margarita Prokofilevna" e "Mamåo, Rimma $\Theta$ Alla".

9 Alusăo ao trulo do $2^{\circ}$ volume da trilogia autoblográflca de Górki, Ganhando meu pâo, tftulo este que tem. tambêm, um sentido mais amplo.

10 Siglas de TCHErezvitchálnaia Komfssia (Comissấo Extraordinária), a polfcia polftica criada em 1918 e de NARódni KOMissariát PROSveschê nia (Comissariado do Povo para a Instruçăo).

11 Expediçరôs ao campo para requisiçăo de generos alimentícios.

12 O general russo Nikolal N. ludiénitch (1862-1933), que conduziu as tropas antibolcheviques numa tentativa frustrada contra Petrogrado em 1919.
Nas vésperas de sábado, sinto-me oprimido pela tristeza densa das recordações. Outrora, nessas noites o meu avô afagava com a barba amarela volumes de Ibn-Ezra(1). Minha avర, de touca de renda, murmurava, movendo os dedos nodosos sobre a vela de sábado, e chorava com doçura. Meu coração infantil balouçava-se nessas noites, qual navio em águas encantadas...

Vagueio por Jitômir, à procura da tímida estrela. Junto à sinagoga antiga, de muros indiferentes e amarelos, velhos judeus vendem giz, anil, pavios - judeus com barbas de profeta, de andrajos ardentes sobre o peito caído...

Tenho diante de mim o mercado e a morte do mercado. Foi morta a alma gorda da abundância. Cadeados mudos estão suspensos nas barracas, e o granito do calçamento é liso qual crânio de defunto. O calçamento pisca e se apaga, tímida estrela...

Foi mais tarde que me veio o êxito, pouco antes do pôr-do-sol. A venda de Guedáli escondeu-se na fila dos armazens bem fechados. Dickens, onde estava nessa noite a tua sombra? Haverias de ver nessa lojinha de antigüidades sapatinhos dourados e cordame de navio, uma bússola antiga e uma águia empalhada, uma Winchester de caça com a data " 1810 " gravada e uma caçarola partida.

O velho Guedáli caminha em volta dos seus tesouros no vazio cor-de-rosa do anoitecer - é o miúdo proprietário, de óculos cinéreos e sobrecasaca verde, que vai até o chão. Esfrega as mãozinhas brancas, belisca a barba cinzenta e, a cabeça inclinada, escuta vozes invisíveis, que acorreram ao seu encontro.

Essa loja parece uma caixinha pertencente a um menino curioso e solene, que há de se tornar catedrático de Botânica. Nessa lojinha encontram-se tanto botões como uma borboleta morta. $\mathrm{O}$ seu pequeno dono chama-se Guedáli. Todos abandonaram o mercado. Guedáli ficou. Ele se retorce no labirinto dos globos, das caveiras e das flores mortas, sacode a vassoura colorida de penas de galo, e espana a poeira das flores defuntas.

Ficamos sentados sobre barris de cerveja vazios. Guedáli enrola e desenrola a barba estreita. A sua cartola balança-se sobre nós, qual uma torrezinha negra. Escorre um ar tépido. O céu muda de cor. Um sangue terno se verte da garrafa derrubada lá em cima, e envolve-nos um leve odor de decomposição.

- Nós vamos dizer "sim" à Revolução, mas temos acaso de dizer "não" ao Sábado? - começa Guedáli e enreda-me nos cintos de seda dos seus olhos fumarentos. - Eu grito "sim" à Revolução, mas ela se esconde de Guedáli e envia à frente apenas fuzilaria...

- O sol não entra em olhos fechados - respondo eu ao velho -, mas nós abriremos à força os olhos fechados...

- O polaco fechou-me os olhos - murmura o velho, quase imperceptível. O polaco e um cão danado. Ele pega o judeu e arranca-lhe a barba, ah, cachorro! Mas agora o apanham e batem nesse cão danado. Isto é formidável, é a Revolução! E depois aquele que bateu no polaco me diz: "Entrega, para controle, o teu gramofone, Guedáli..." "Eu gosto da música, meu senhor" respondo eu à Revolução. "Você não sabe do que você gosta, Guedáli, vou atirar em você, então vai aprender isto, eu não posso deixar de atirar, porque eu sou a Revolução..." ção...

- Ela não pode deixar de atirar, Guedáli - digo ao velho - porque ela é a Revolu-

- Mas o polaco atirava, meu caro senhor, porque ele era a Contra-Revolução. Vocês atiram, porque são a Revolução. Mas a Revolução é alegria. E a alegria não gosta de ter órfãos em casa. Um homem bom pratica obras boas. A Revolução é uma boa obra de gente boa. Mas gente boa não mata. Quer dizer que a Revolução é feita por gente ruim. Mas os polacos também são gente ruim. Quem vai então dizer a Guedáli onde está a Revolução e onde está a Contra-Revolução? Eu estudei outrora o Talmud, gosto dos comentários de Rachi e dos livros de Maimônides ${ }^{(2)}$. E em Jitômir existem ainda outros homens de saber. E eis que todos nós, homens de saber, caímos com a face contra o solo e gritamos: "Ai de nós, onde está a doce Revolução?..."

O velho se calou. E nós vimos a primeira estrela, abrindo seu caminho ao longo da Via Láctea.

- Está chegando o sábado - disse gravemente Guedáli -, os judeus têm de ir à Sinagoga, Senhor Camarada - prosseguiu erguendo-se, e a cartola balançou-se-lhe sobre a
$\mathrm{R}$

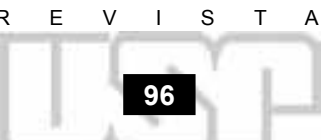


cabeça, qual uma torrezinha negra -, traga a Jitômir um pouco de gente boa. Ai, eles fazem falta em nossa cidade, ai, como fazem falta! Traga gente boa, e nós entregaremos a ela todos os gramofones. Não somos ignorantes... A Internacional... nós sabemos o que é a Internacional. Também eu quero uma Internacional das pessoas de bem, quero que toda alma seja registrada e que se lhe dê uma ração de primeira categoria. Aí está, alma, faça o favor de comer, tire o seu prazer da vida. A Internacional, Senhor Camarada, o senhor não sabe com o que ela se come...

- Ela se come com pólvora - respondi ao velho - e tempera-se com sangue de primeira.

E eis que o jovem sábado saiu da treva azul e subiu ao seu trono.

- Guedáli - digo eu -, hoje é sexta-feira e já chegou a noite. Onde se pode conseguir uma bolachinha judia, um copo de chá judeu e um pouco daquele Deus demissionário que sobrou num copo de chá?...

- Em parte alguma - responde-me Guedáli, pendurando um cadeado em seu cochicholo - não há mais. Aqui ao lado, fica uma taverna, e pessoas de bem tinham aí seu comércio, mas nela não se come mais, nela se chora...

Abotoou a sobrecasaca verde com os três botões de osso. Espanou-se com as penas de galo, borrifou água nas palmas macias das mãos e afastou-se: minúsculo, solitário, sonhador, de cartola negra e com um grande livro de orações sob a axila.

O sábado se aproxima. Guedáli, o fundador de uma Internacional quimérica, foi à Sinagoga rezar.

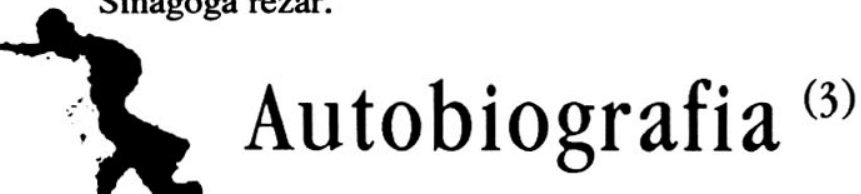

- Tradução e notas de PAULO DAL-Ri PERES

Nasci /em 1894/ em Odessa, na Moldavanka, filho de um comerciante judeu. Por insistência de meu pai, até os 16 anos, estudei a língua hebraica, a Bıblia e o Talmud. Em casa /era difícil viver, porque/, de manhã à noite, obrigavam a estudar inúmeras ciências. Descansava na escola. Ela se chamava Escola Comercial de Odessa "Imperador Nicolau I". Era uma escola livre, ruidosa, barulhenta e multilíngua ${ }^{(4)}$. Lá estudavam os filhos de comerciantes estrangeiros, corretores judeus, /nobres/ poloneses de origem nobre, velhos crentes ${ }^{(5)}$ e muito rapagōes jogadores de bilhar. Às vezes, nos intervalos, escapávamos para o cais do porto, ou aos cafés gregos para jogar bilhar, ou à Moldavanka para beber, nas adegas, vinho barato da Bessarábia. /A escola é ainda mais inesquecível para mim porque o professor de francês era Mr. Vadon/ A melhor das matérias era francês. $O$ professor era bretão e possuía dons literários, como todos os franceses. /Ele ensinou-me sua língua e eu/ Decorei com ele os clássicos /franceses/, entrei em contato estreito com a colônia francesa de Odessa e, aos 15 anos, comecei a escrever contos em francês./ Escrevi-os durante dois anos mas, depois, deixei. Os paysans( ${ }^{(6)}$ e quaisquer pensamentos de autor safam-me apagados, somente o diálogo me safa bem./

/Depois,/ Terminada a escola, mandaram-me para Kiev e, em 1915, fui parar em Petersburgo. Lá, me vi /terrivelmente/ mal, não tinha permanência" e evitava a polícia abrigando-me Púchkin, em casa de um garçon bêbado e aniquilado. 1915 , comecei a levar meus escritos às redações, parte, enxotavam-me e os redatores (o falecido outros) tentavam persuadir-me a trabalhar como loja, não /os/ escutei e, no final de 1916, encontrei sim, eu/ Devo tudo a este encontro /e até hoje "direito de em porões na rua /Então,/ Em /mas/ em toda Ismáilov, Possé e vendedor numa Górki. /E, asprofiro o nome de Aleksei Maksímovitch com amor e veneração/. Górki publicou meus primeiros contos no número de novembro de 1916 da Liétopis $^{(7)}$. (Por causa desses contos fui chamado à responsabilidade /penal/ segundo o artigo $1001 / \mathrm{do}$ código $\left.^{(8)} /\right)$. Ele me ensinou coisas /extremamente/ importantes e, depois, quando ficou claro que duas ou três experiências /juvenis/ suportáveis haviam sido, simplesmente, um sucesso casual e com a literatura eu não estava conseguindo nada, que eu escrevia surpreendentemente mal, Aleksei Maksímovitch mandou-me para o mundo ${ }^{(9)}$.

/E eu,/ Durante sete anos, de 1917 a 1924, tive muito que aprender. /Nessa época,/ Fui soldado na frente romena, depois servi na Tcheka, no Narkompros ${ }^{(10)}$, nas expedições de Abastecimento de $1918^{(11)}$, no exército do Norte contra Iudiênitch ${ }^{(12)}$, no Primei- 


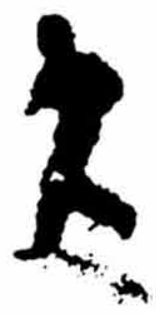

13 Criado em 17/11/1919, sob o comando do general Budionni. Bábel participou dele durante a guerra russopolonesa de 1920, onde fez as ano polonesa de 1920, onde fez as ano-
taçes que serviram de base para seu livro de contos Cavalaria vermelha.

14 Sigla de Lievil Front Iskusstva (Frente de Esquerda da Arte), publicaçăo pe-
riodica (1923-25) cubo-futurista, dirigida por Maiakovski. Bâbel se equivoca - estes contos foram publicados no número 4 de 1923 e năo em 1924.

15 Este parágrafo e a bibliografia que 0 segue aparecem na versåo corrigida de 1932.

16 Primeira publicaçăo em almanaque Vozdúchnie puti (Vias aéreas) $n^{2} 3$, Nova York, 1963. A primeira publica. çăo soviética ế de 1964. Gratch significa "gralha".

17 Nome atribufdo por Bábel ao chefe dos 40.000 bandidos que atuaram em Odessa no perfodo da Guerra Civil, que aparece nos Contos de Odessa. Krik significa "grito".

18 Os exércitos brancos conduzidos pelo general tzarista Wrangel.

19 Apropriaçấo de valores determinada pelo Soviete de Odessa, no infcio da Revoluçăo.

20 Assoclaçấo de operários de uma mesma profissăo. No caso, trata-se de bancários ou de trabalhadores que teriam ocupado o banco. Parece estranho os bandidos "apresentarem um pedido" num assalto. Sabemos por outros contos do autor que esta $\theta$ uma caracteristica de Benla Krik: ele considera seus assaltos como "assuntos comerciais" - envia cartas no estilo correspondente o ato discute a situaçăo do mercado internacional.

21 Bairro à beira-mar, em Odessa.

22 Um tipo de charrete.

23 Tropas da Argella e do Senegal, trazidas pelos franceses durante a intervençăo estrangeira contra a URSS.

24 Diminutivo de Aleksandr.

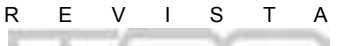

ro Exército de Cavalaria(13), no comitê Provincial de Odessa, fui expedidor na Sétima Tipografia Soviética em Odessa, reporter em Petersburgo e Tfflis etc. E, somente em 1923, consegui expressar meus pensamentos de um modo claro e não muito longo. /Então, eu novamente me pus a escrever./

Por isso, refiro o iń́cio do meu trabalho literário ao /começo do/ ano de 1924, quando meus contos "Sal", "Uma carta", "A morte de Dolguchóv", "O rei" e outros apareceram na /no 40 número da /revista LEF(14).

Durante dois anos foram escritos Cavalaria vermelha e Contos de Odessa. Depois, veio novamente o tempo das peregrinações, do silêncio e da acumulação de forças. E, agora, diante de mim tenho um novo trabalho(15).

\section{Contos de Odessa.}

Contos, Ed. "Ogoniбk", Moscou, 1925.

Contos, 1925, GIZ; 2 ed., 1927.

Historia do meu pombal. Contos. ZIF, Moscou, Leningrado, 1926.

Estrelas errantes. Roteiro cinematográfico. Moscou, "Kinopetchátel", 1926.

Bênia Krik. Cine-novela. Ed. Krug, Moscou, 1926.

O fim de S. Ipátio. Contos. "ZIF" Moscou, 1926.

Cavalaria vermelha. Contos. GIZ, Moscou, Leningrado, 1926, 2 ed., GIZ, 1927.

$O$ crepúsculo. Peças. Ed. Krug. Moscou, 1928.

\section{Froim Gratch ${ }^{(16)}$}

Traduçăo e notas de PAULO DAL-RI PERES

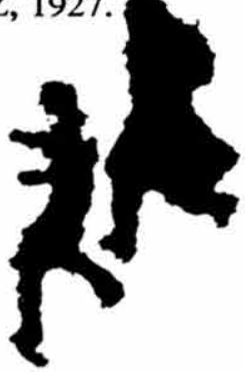

Em 1919, os homens de Bênia Krik ${ }^{(17)}$ atacaram a retaguarda das Tropas Voluntárias $^{(18)}$, esfaquearam os oficiais e apoderaram-se de parte do comboio. Como recompensa exigiram do Soviete de Odessa três dias de "insurreição pacffica"(19), mas não receberam autorização e por isso saquearam os tecidos de todas as lojas situadas na Avenida Aleksándrovski. Em seguida, dirigiram suas atividades para a Sociedade de Crédito Mútuo. Empurrando os clientes, entraram no Banco e apresentaram aos membros do artie $^{(20)}$ um pedido para depositarem sacos com dinheiro e joias num automóvel que esperava na rua. Passou-se um mês antes que se começasse a fuzilá-los. Houve quem dissesse que Aron Piéskin, proprietário de uma oficina, tinha algo a ver com as capturas e prisões. Não se estabeleceu em que consistia o trabalho daquela oficina. No apartamento de Piéskin havia um instrumento, máquina comprida com eixo de chumbo retorcido. No chão, serragem e papelão para encadernar.

Numa manhã de primavera Micha Iáblotchko, um amigo de Piéskin, bateu à porta da oficina.

- Aron - disse o visitante a Piéskin -, lá fora está um tempo maravilhoso. Você tem em minha pessoa um tipo capaz de tomar contigo meia garrafa com antepasto a gosto e dar um passeio ao ar livre, na Arcádia(21)... Você pode rir de um tipo assim, mas eu gosto, às vezes, de livrar da cabeça estes pensamentos todos...

Piéskin vestiu-se e foi com Micha Iáblotchko de steiger ${ }^{22)}$ para a Arcádia. Passearam até o fim da tarde; ao anoitecer, Micha Iáblotchko entrou no quarto onde madame Piéskina lavava numa tina a filha de catorze anos.

- Salve - disse Micha, tirando o chapé -, passamos umas horas maravilhosas. $\mathrm{O}$ ar está qualquer coisa de excepcional, mas é preciso armar-se de paciência antes de falar com teu marido... Ele tem um gênio diff́cil.

- É para mim que você conta isso? - exclamou madame Pieskina, agarrando a filha pelos cabelos e sacudindo-a em todas as direções. - Onde está este aventureiro?

- Descansando no jardim.

Micha pôs novamente o chapéu, despediu-se e partiu no steiger. Madame Piéskina nem esperou o marido entrar - foi procurá-lo no jardim. Ele estava sentado apoiando-se na mesa, usando um panamá e com os dentes arreganhados.

- Aventureiro - disse-lhe madame Piéskina -, você ainda ri... Vou ter um ataque por causa da tua filha, ela não quer lavar a cabeça... Vá ter uma conversa com ela...

Piéskin permanecia calado e com osd entes arreganhados. 
- Vagabundo - começou madame Piéskina, espiou para debaixo do panamá e gritou. Os vizinhos vieram correndo.

- Ele não está vivo - disse-lhes madame Piéskina. Está morto.

Enganava-se. Piéskin tinha o peito perfurado em dois locais e uma fratura craniana, mas ainda vivia. Levaram-no ao hospital judeu. O próprio doutor Silberberg operou o ferido, mas Piéskin não teve sorte e morreu sob o bisturi. Nesta mesma noite, a Tcheká prendeu um indivíduo apelidado "Georgiano" e seu amigo Kólia Lápidus. Um, era o cocheiro de Micha Iáblotchko, o outro, esperava o carro na Arcádia, na praia junto à curva que dá para a estepe. Fuzilaram-nos após um interrogatório sumário. Somente Micha Iáblotchko escapou da emboscada. Sua pista se perdeu e passaram-se alguns dias até que uma velha, vendedora de sementes de girassol, surgisse no pátio da casa de Fróim Gratch. Carregava a cesta dos seus produtos debaixo do braço. Uma de suas sobrancelhas, moita densa, negra como carvão, aparecia no alto e a outra, apenas esboçada, arqueava-se sobre a pálpebra. Fróim Gratch, esparramando as pernas, estava sentado junto à estrebaria e brincava com o neto Arkádi. Este menino desprendera-se, três anos antes, do útero possante de sua filha Baska. O avô estendeu um dedo a Arkádi, que o agarrou, suspendeu-se e ficou balançando-se, como numa barra.

- Você não vale nada... - disse Fróim ao neto, olhando-o com seu único olho.

A velha da sobrancelha densa e botinas masculinas atadas com barbante aproximouse dele.

- Fróim - disse a velha -, eu te digo que esta gente não é humana. É gente sem palavra. Massacraram-nos nos sótãos como cachorros numa fossa. Nem nos permitem dizer uma palavra antes da morte... É preciso roer esta gente com os dentes e arrancar-lhes o coração... Você continua calado, Fróim - acrescentou Micha Iáblotchko -, os rapazes estão esperando você começar a falar...

Micha ergueu-se, passou a cesta de uma à outra mão e saiu, erguendo a sobrancelha negra. Três meninas de tranças entrelaçadas cruzaram com ele, na praça Alekséievskaia, junto à igreja. Passeavam, abraçadas pela cintura.

- Senhoritas - disse-lhes Micha Iáblotchko -, não vou lhes oferecer chá com biscoitos...

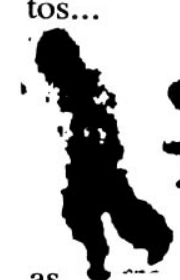

Com ajuda de um copo, despejou-lhes as sementes de girassol no bolso dos vestidinhos e desapareceu, contor-

as sombra de Dnen. e tomavam tragos 210 tórridas de vento investiam contra as paredes caiadas e o sol, num torpor azul, derramava-se pelo pátio. Fróim levantou-se e saiu à rua. Atravessou a Prokhórovskaia, que expelia para o céu o fumo miserável e dissolvido de suas cozinhas, e a praça do Belchior, onde pessoas enroladas em cortinas e reposteiros vendiam-nos uns aos outros. Atingiu a rua Ekaterínskaia, virou junto ao monumento da imperatriz e entrou no predio da Tche$k a$.

- Sou Fróim - disse ao comandante -, preciso falar com o patrão.

Naquela época, o presidente da Tcheká era o moscovita Vladislav Símen. Avisado da chegada de Fróim, convocou Borovói, o juiz de instrução, para informar-se sobre o visitante. te...

- É um tipo grandioso - respondeu Borovói -, Odessa inteira vai passar na tua fren-

O comandante introduziu no gabinete um velho coberto por um capotão de lona e enorme como um edifício, ruivo, um olho tapado e com a face desfigurada.

- Patrão - disse o recém-chegado -, quem você está caçando?... Você está caçando águias. Com quem você vai ficar, patrão, com o estrume?...

Símen fez um movimento e entreabriu a gaveta da mesa.

- Estou limpo - disse, então, Frơim -, não tenho nada nas mãos, não tenho nada nas botas e não tenho ninguém na rua... Deixe os meus rapazes, patrão, diga o teu preço.

Acomodaram o velho numa poltrona e trouxeram-lhe conhaque. Borovói saiu e reuniu em sua sala os juízes de instrução e comissários vindos de Moscou.

- Vou lhes mostrar um tipo - disse -, uma epopéia, não existe igual...

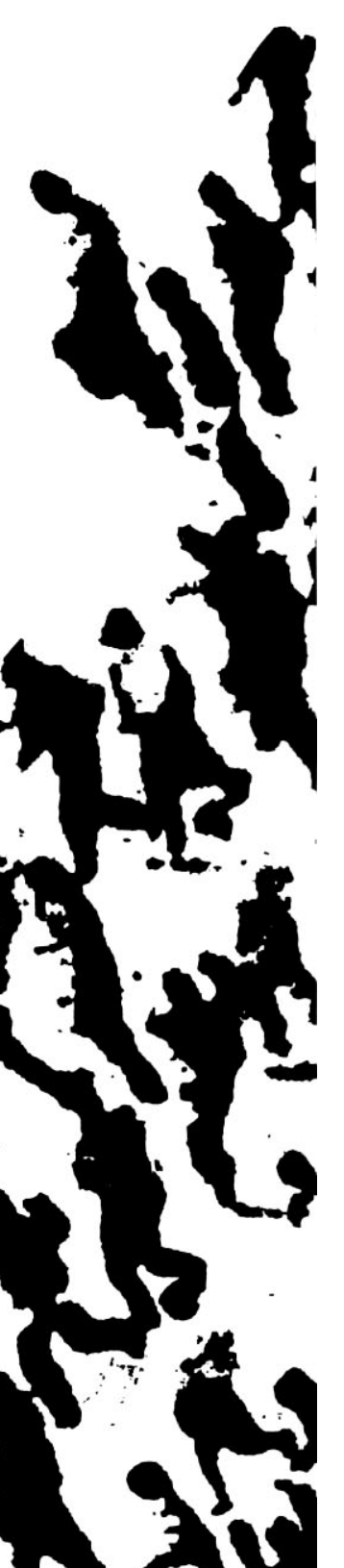




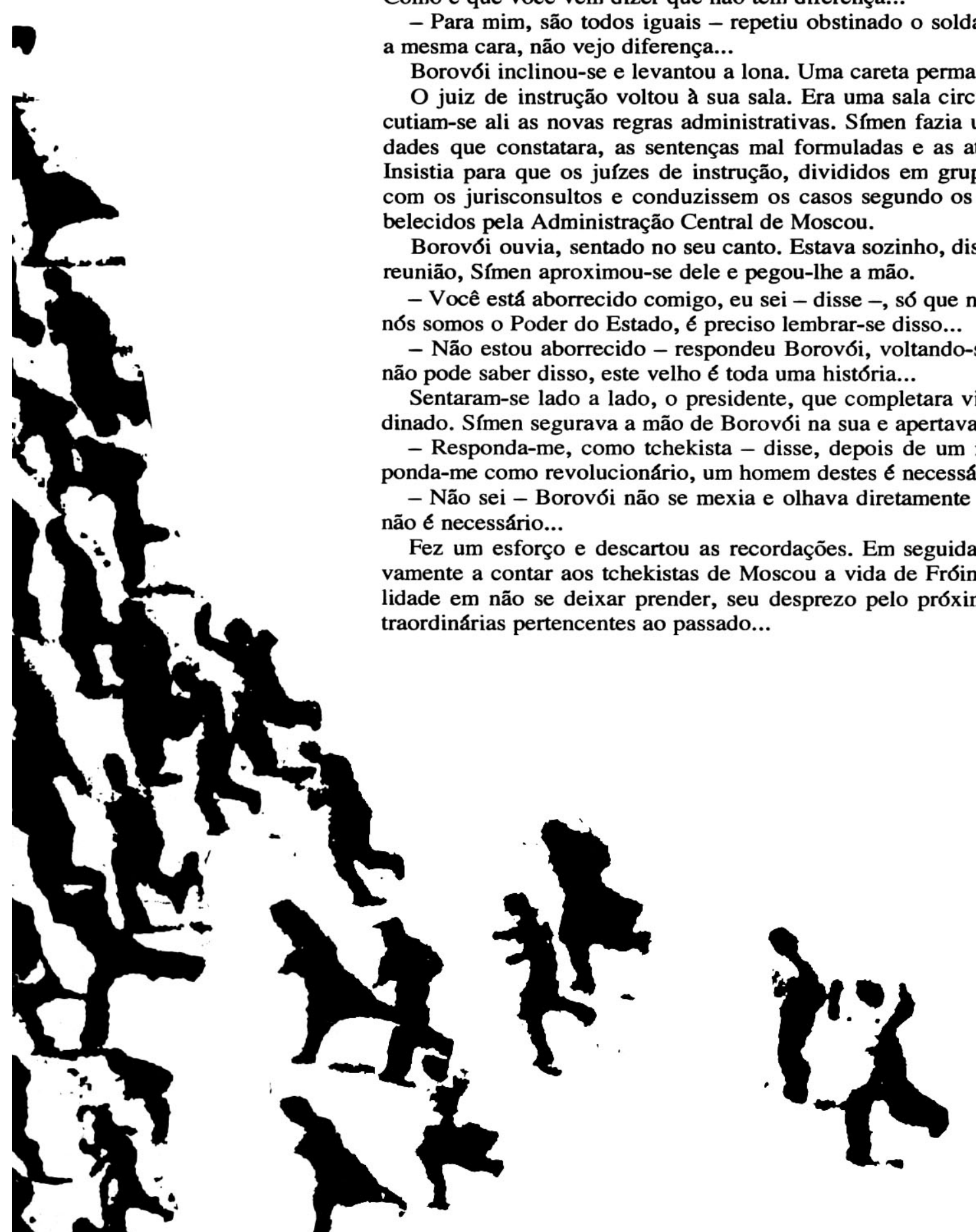

E Borovói contou que o zarolho Fróim, e não Bênia Krik, era o verdadeiro chefe dos quarenta mil ladrões de Odessa. $O$ velho escondia o jogo, mas tudo era executado segundo seus planos - o saque das fábricas e do tesouro de Odessa, os ataques contra os Voluntários e as tropas aliadas. Borovói esperou a safda do velho para conversar com ele. Fróim não aparecia. Cansado de esperar, o juiz saiu à sua procura. Percorreu o prédio inteiro e, para terminar, deu uma olhada no pátio de serviço. Frơim Gratch jazia ali, estendido sob uma lona, junto ao muro coberto de hera. Dois soldados fumavam cigarros improvisados perto do cadáver.

- Um verdadeiro urso - disse o mais velho ao ver Borovói -, uma força incrivel... Se não tivéssemos matado o velho, ele viveria para sempre... Já tinha dez disparos e continuava se mexendo...

O soldado estava todo vermelho, seus olhos cintilavam, o gorro tinha caŕdo para um lado.

- Você diz besteira - interrompeu o outro soldado da escolta -, morto ê morto, não tem diferença...

- Essa não - exclamou o mais velho -, um implora, grita, outro não diz palavra... Como ê que você vem dizer que não tem diferença...

- Para mim, são todos iguais - repetiu obstinado o soldado mais jovem -, todos têm mesma cara, não vejo diferença...

Borovói inclinou-se e levantou a lona. Uma careta permanecia no rosto do velho.

$\mathrm{O}$ juiz de instrução voltou à sua sala. Era uma sala circular, forrada com seda. Dis-

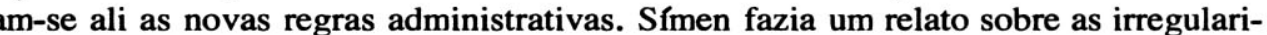
os formulários e modelos estaelecidos pela Administração Central de Moscou.

, distante dos demais. Depois da Símen aproximou-se dele e pegou-lhe a mão.

os somos o Poder do Estado, é preciso lembrar-se disso...

estou aborrecido - respondeu Borovói, voltando-se -, você não é de Odessa,

Sentaram-se lado a lado, o presidente, que completara vinte e três anos, e seu suborinado. Símen segurava a mão de Borovới na sua e apertava-a.

Responda-me, como tchekista - disse, depois de um momento de silêncio -, res-

o é necessário...

Fez um esforço e descartou as recordações. Em seguida, reanimando-se, pôs-se noFróm Gratch, sua astúcia e habiidade em não se deixar prender, seu desprezo pelo próximo, todas estas histórias extraordinárias pertencentes ao passado... 